\title{
DOMINIQUE MILLET-GÉRARD, Paul Claudel et les Pères de l'Église
}

\section{Riccardo Benedettini}

\section{(2) OpenEdition}

\section{Journals}

\section{Edizione digitale}

URL: https://journals.openedition.org/studifrancesi/12075

DOI: 10.4000/studifrancesi. 12075

ISSN: 2421-5856

\section{Editore}

Rosenberg \& Sellier

\section{Edizione cartacea}

Data di pubblicazione: 1 avril 2018

Paginazione: 164

ISSN: 0039-2944

\section{Notizia bibliografica digitale}

Riccardo Benedettini, «Dominique millet-gérard, Paul Claudel et les Pères de l'Église», Studi Francesi [Online], 184 (LXII | I) | 2018, online dal 03 juillet 2018, consultato il 17 novembre 2021. URL: http://

journals.openedition.org/studifrancesi/12075 ; DOI: https://doi.org/10.4000/studifrancesi.12075

Questo documento è stato generato automaticamente il 17 novembre 2021 .

\section{(2) $\odot \Theta \Theta$}

Studi Francesi è distribuita con Licenza Creative Commons Attribuzione - Non commerciale - Non opere derivate 4.0 Internazionale. 


\title{
DOMINIQUE MILLET-GÉRARD, Paul Claudel et les Pères de l'Église
}

\author{
Riccardo Benedettini
}

\section{NOTIZIA}

DOMINIQUe MILLET-GÉRARD, Paul Claudel et les Pères de l'Église, Paris, Champion, 2016,

«Poétiques et esthétiques $\mathrm{Xx}^{\mathrm{e}}$-XXI ${ }^{\mathrm{e}}$ siècles» 30, $484 \mathrm{pp}$.

1 Questa monografia costituisce uno studio ampio e documentato su Claudel e i Padri della Chiesa. Dominique Millet-Gérard, che aveva già scritto molto sul poeta (rammento solo: Anima et la Sagesse, 1990; Claudel thomiste, 1999; Claudel, la Beauté et l'Arrière-Beauté, 2000; La prose transfigurée, 2005, alcuni volumi di corrispondenze, 2005, 2008, 2012; numerosi articoli su rivista $\mathrm{o}$ in atti di convegno), propone ora, già a partire da un'intelligente e acuta «Introduction» (pp. 11-16), una serie di interrogativi che torneranno nel testo, acquisendo un preciso rilievo e cercando di presentare delle risposte al quesito «Que représentent ces "Pères" pour Claudel?» (p. 13). Questi grandi scrittori, ispirati, costituiscono una facile auctoritas per Claudel o sono invece un riferimento sicuro, risultato di vaste e precise letture, si chiede l'A. che, per la definizione di Padri della Chiesa, rinvia alla categoria fissata dalla concezione tridentina.

2 Nei sedici capitoli in cui è articolato il volume, l'A. dedica la prima parte del libro («La découverte des Pères par Claudel», pp. 17-82) alle letture giovanili di Claudel fino al 1927 (Pascal, Bossuet, Dante), ad un periodo di apprentissage sur le tas che va dal 1929 al 1941, all'età d'oro della patristica claudélienne che arriverà fino alla morte del poeta, avvenuta nel febbraio 1955. La seconda parte («Les Pères fondateurs: Grégoire, Augustin, Denys», pp. 83-191) sottolinea come la lettura fatta da Claudel dei Padri fosse molto più intuitiva che erudita: il soffermarsi sui tre nomi più frequenti e sui grandi temi patristici - o reputati tali - illustrati dal poeta, permette di indicare le ragioni stilistiche dell'interesse di Claudel per i Padri della Chiesa: sorta di maîtres à penser, la 
loro influenza sembra ben combinarsi col lettore fantaisiste. La terza parte («Le "bédouin de l'exégèse" et la caution des Pères», pp. 193-297) riprende i documenti mostrati in precedenza e intende mettere in luce il rapporto di Claudel, scrittore di testi direttamente dedicati alla Bibbia, con il mondo degli esegeti, centrale nella Francia del periodo: la questione patristica, qui studiata anche rinviando agli intermediari cui Claudel ricorse (quei «vecteurs, filtres et paravents», Pascal e Bossuet, che danno il titolo al primo capitolo di questa sezione), diventa un modo per difendere la propria lettura del testo sacro. Infine, la quarta parte («Poétique patristique», pp. 299-421) pone Claudel nel campo degli ermeneuti più che in quello degli esegeti: il testo sacro è la lingua di Dio, portatore di un significato non solo spirituale ma anche del segreto del linguaggio: «C'est dire que scruter le texte sacré et en découvrir le tissu figuratif est une participation au double acte créateur divin» (p. 436), come è ripreso nella «Conclusion» (pp. 423-436). Il volume si chiude con una «Bibliographie» (pp. 437-457) e tre indici: «Index des œuvres de Claudel» (pp. 459-462), «Index biblique» (pp. 463-468) e «Index nominum» (pp. 469-479). 